\title{
Patients' ideas, concerns, and expectations (ICE) in general practice: impact on prescribing
}

\author{
Jan Matthys, Glyn Elwyn, Marc Van Nuland, Georges Van Maele,
} An De Sutter, Marc De Meyere and Myriam Deveugele

\author{
ABSTRACT \\ Background \\ Although studies are available on patients' ideas, \\ concerns, and expectations in primary care, there is a \\ scarcity of studies that explore the triad of ideas, \\ concerns, and expectations (ICE) in general practice \\ consultations and the impact on medication prescribing. \\ Aim \\ To evaluate the presence of ICE and its relation to \\ medication prescription. \\ Design of study \\ Cross-sectional study. \\ Setting \\ Thirty-six GP teaching practices affiliated with the \\ University of Ghent, in Flanders, Belgium.

\section{Method} \\ Participants were all patients consulting on 30 May \\ 2005, and their doctors. Reasons for an encounter \\ (consultation or home visit) with new and follow-up \\ contacts, the identification of ICE, and the prescription \\ of medication were recorded by 36 trainee GPs \\ undergoing observational training. The study included \\ 613 consultations. \\ Results \\ One, two, or three of the ICE components were \\ expressed in $38.5 \%, 24.4 \%$, and $20.1 \%(n=236,150$, \\ 123) of contacts respectively. On the other hand, in \\ $17.0 \%(104 / 613)$ of all contacts, and in $22 \%(77 / 350)$ of \\ the new contact reasons, no ICE was voiced, and the \\ GPs operated without knowing this information about \\ the patients. Mean number of ICE components per \\ doctor and per contact was 1.54 (standard deviation = \\ 0.54). A logistic regression analysis of the $350 \mathrm{new}$ \\ contacts showed that the presence of concerns $(P=$ \\ 0.037 , odds ratio $[\mathrm{OR}] 1.73,95 \%$ confidence interval \\ $[\mathrm{Cl}]=1.03$ to 2.9$)$, and expectations $(P=0.009$, $\mathrm{OR}=$ \\ $2.0,95 \% \mathrm{Cl}=1.2$ to 3.4 ) was associated with not \\ prescribing new medication (dichotomised into the \\ categories present/absent); however, other patient, \\ doctor, and student variables were not significantly \\ associated with medication prescription.

\section{Conclusion} \\ An association was found between the presence of \\ concerns and/or expectations, and less medication \\ prescribing. The data suggest that exploring ICE \\ components may lead to fewer new medication \\ prescriptions.

\section{Keywords} \\ communication; counselling; medication; medical \\ education; prescription.
}

\section{INTRODUCTION}

Good communication is central to high-quality medical care. This idea is supported by systematic reviews of the literature showing that improving the interaction between patients and practitioners may have positive effects on health-related outcomes. ${ }^{1,2}$ Similar results were found in a review of studies performed exclusively within the field of primary care. ${ }^{3}$

There has been a shift towards patient-centred communication, ${ }^{4-6}$ and some comprehensive frameworks, such as the Calgary-Cambridge Observation Guide, have been developed. ${ }^{7}$ Acquisition of communication skills has gained more interest in medical curricula during recent decades. ${ }^{8,9}$

Disclosure by patients of their ideas, concerns, and expectations about diagnosis and/or treatment, brought together in the ICE acronym, is a part of 'gathering information' within the communication framework and exemplifies a patient-centred approach. Not only may this disclosure provide more insight into the reasons for an encounter (consultation or home visit), it may also be a clue to establishing the right diagnosis. Moreover, it influences the process of (shared) decision making and will hopefully enhance

G Van Maele, professor of statistics, Department of Statistics; J Matthys, MD, vocational trainer; A De Sutter, professor of general practice; $M$ De Meyere, professor of general practice; M Deveugele, professor of medical psychology; Department of General Practice and Primary Health Care, Ghent University, Belgium; M Van Nuland, MD, GP, Department of General Practice and Primary Health Care, Catholic University of Leuven, Belgium. G Elwyn, professor of primary care medicine, Department of Primary Care and Public Health, Cardiff University, Cardiff.

\section{Address for correspondence}

Dr Jan Matthys, Ghent University, General Practice and Primary Health Care, De Pintelaan 185, Ghent, 9000, Belgium.E-mail: jan.matthys@ugent.be

Submitted: 15 January 2008; Editor's response: 26 March 2008; final acceptance: 19 June 2008.

(c)British Journal of General Practice

This article was originally online first. Cite this article as: Br J Gen Pract 2009; 58: 29-36. Advance online publication. DOI: $10.3399 /$ bjgp09X394833 


\section{How this fits in}

Until now, it has not been possible to find studies that explored the triad of

ideas, concerns, expectations (ICE) in general practice consultations, and the

impact on medication prescribing. In this study, the ICE components (ideas

and/or concerns and/or expectations) appeared regularly, but not

systematically. In particular, an association was found between the presence of

concerns and expectations and less medication prescribing. Because the link

between communication and prescribing is relevant, and because it is possible

that exploring ICE components leads to fewer new medication prescriptions, it

is hoped that more explorations in this field will be seen.

patients' compliance. The importance of the disclosure of patients' ideas, concerns, and expectations, is often emphasised in the leading medical communication literature. ${ }^{4,7,8,10}$

To the authors' knowledge, one paper has focused on concerns, expectations, and ideas in the context of shared decision making. ${ }^{11}$ The study, which used transcripts of medical consultations, indicated that GPs are able to elicit ideas, concerns, and expectations from patients (expectations about diagnosis, but not about management).

At Ghent University, Belgium, undergraduate medical students learn, as a part of communication training, the skills needed to ask questions about ICE components. The authors strongly believe that these skills can help students to achieve a patient-centred approach. ${ }^{12}$

Recently, the ICE concept has been incorporated as a standard item in one of the major medical software programmes for GP electronic medical record keeping in Belgium (Medigest-Corilus, version 2006.1-1).

The present research arose from an interest in the expression of ICE elements during the consultation, either by patients answering the doctors' questions, or through spontaneous disclosure. Therefore, this study investigated the presence of ICE components during clinical encounters in GP teaching practices and the impact of ICE components on prescribing.

There is a possible relationship between communication training and medication prescribing as an outcome measure. However, there is a paucity of literature concerning this relationship; only one trial in general practice was identified and it found no influence of communication training on an antibiotic prescription rate (of $15.7 \%$ ), which was already unusually low..$^{13}$

It was hypothesised that knowledge of patients' ideas and/or concerns and/or expectations could improve the understanding of patients' aims, ${ }^{14}$ and could have an impact on medication prescribing. This idea was a direct result of a feasibility study of recording ICE components in medical records in one teaching practice, with 10 students in observational training. ${ }^{15}$ Although doctors usually prescribe the medication they think their patients really need, doctor-patient interaction is important, and prescribing is not purely evidence based. The hypothesis for this study was that disclosing ICE components (ideas, concerns, and expectations), either spontaneously by the patient or verbally elicited by the GP, would lead to less new medication prescribing. This hypothesis is supported by the work of Cartwright and Anderson, who in 1981 set out clearly that patients seemed to want to receive a prescription less often than their doctors thought they did. ${ }^{16}$

Furthermore, the literature shows that patients' expectations often correlate poorly with physicians' perceptions of these expectations. ${ }^{17-28}$

The aim of the present study was to explore different aspects during the encounter with patients and to separate ideas and concerns and expectations. Research questions were twofold:

- To what extent do ideas, concerns, and expectations appear in the consultation, either as expressed by the patient or as elicited by the doctor?

- Is there any correlation between the expression of ICE components and prescription rate?

\section{METHOD}

\section{Setting}

The study took place in 36 GP teaching practices in Flanders, Belgium.

\section{Participants}

Doctors. The GPs received a letter informing them about a registration project by students in observational training. To avoid bias, GPs were told that the study aimed to examine patients' reasons for an encounter, so that the observed doctors were not aware of the hypothesis of the study. All participating GPs gave written informed consent.

Patients. Consultations were made with a GP and a GP trainee present. A poster in the waiting room notified patients of the presence of a student, and mentioned that each patient had the opportunity to ask to see the GP without the student present. In academic teaching practices, patients are accustomed to the presence of students: the teaching practices had, on average, experience with 17 trainees in the past. ${ }^{29}$

\section{Measures}

All GP trainees $(n=39)$ undergoing observational training were asked to observe and record patients' expressions of ideas, concerns, and expectations during the consultations and home visits in their 
training practice on 30 May 2005. Student participation in the project was voluntary.

\section{Definitions}

'Idea' was defined as every opinion of the patient about a possible diagnosis, treatment, or prognosis; 'concern' as the expressed fear/worry of the patient about a possible diagnosis or treatment; and 'expectation' as the expressed or reported expectation about a treatment, a diagnosis, or a certificate. (Box 1).

At the beginning of the consultation, students recorded whether the patient was attending as a new or a follow-up contact, that is, whether they were consulting the GP about a particular condition for the first time, or whether it was a follow-up contact for a health issue that had been previously discussed with the GP. Registration was based on each patient's history or medical record or, in case of doubt, on the doctor's additional information.

Students recorded all consecutive doctor-patient encounters, noting the patients' age, sex, and educational level (higher education or not), all new medication (prescription medication; topical medications such as ointments, creams, or gargles; and free over-the-counter products, for example, paracetamol, and cough syrups), and continuation of established medication, if applicable. Students also recorded diagnostic management, such as clinical and technical investigations, and other treatments such as self-care, diet, physiotherapy, and referral.

\section{Preparation of the students for recording ICE}

During their medical curriculum, students were trained to elicit ICE through role-playing and video-training

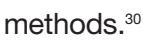

One week before the start of their training, students, in three groups of 13 , received an introductory training on the registration task. Training provided definitions and examples of ideas, concerns, and expectations. The presence of ICE was documented either as expressed by the patient or as revealed by the GP. Students provided a written report of the apparent ideas/concerns/expectations by paraphrasing the words of the patient or doctor. Students also scored the presence/absence of each ICE element with a yes or no (Box 1).

\section{Assessment of reasons for the encounter}

Students were asked to report all reasons for the encounter and all possible complaints. However, for methodological clarity and reliability, students were required to identify one main reason for each encounter, which had to be connected to a diagnostic and therapeutic process, and related to the possible ICE component(s). It was assumed that two reasons for the encounter related to a full diagnostic and therapeutic process were very unlikely to occur. Ideas, concerns, and expectations were considered present (score 1) or absent (score 0) without taking into account whether there was one or more. Influencing or distorting the results with concomitant ICE components from additional reasons for an encounter was considered undesirable. The minimum ICE-score for one full diagnostic and therapeutic process was zero, the maximum ICE score was 3.

Evaluation of the registrations was performed by the main investigator and two raters who were familiar with the registration of ICE. They evaluated the reasons for encounters, whether the recorded ideas, concerns, and expectations related directly to diagnosis or therapy, and whether the ICE score (absent/present) of the student was concordant with the paraphrasing. In cases where paraphrasing was considered insufficient or the evaluators disagreed about the paraphrase or assessment by the student, the score was zero (assessed as no ICE component present). Classification was based on the operational definitions (Box 1).

\section{Box 1. Registration form that GP trainees used to record possible ideas, concerns, and expectations of patients.}

Reason for contact, orally expressed by the patient:

For example, 'I have requested a consultation because of ...'

Ideas Are the ideas of the patient about a possible diagnosis, treatment, or prognosis expressed in the consultation? (Yes/No)

If yes, what ideas are expressed?

Concerns Is concern (fear/worry) of the patient about a possible diagnosis or therapy present in the consultation? (Yes/No)

If yes, what are the concerns about?

Expectations Is the expectation (what the patient wants) for a treatment, a diagnosis, or a therapy present in the consultation? (Yes/No)

If yes, what are the expectations of the patient? 


\section{Table 1. Characteristics of patients and doctors in the new contact group and in the follow-up group, \% (n).}

New contacts $(n=350)$

Follow-up $(n=263)$

\begin{tabular}{lcc}
\hline Patients & & \\
Age in years, mean (SD) & $65.2(15.3)$ & $57.2(20.7)$ \\
Males & $41.7(145)$ & $49.8(130)$ \\
Higher education $>18$ years & $29.7(104)$ & $27.4(72)$ \\
Consultation frequency $>4$ /year & $45.4(159)$ & $66.7(176)$ \\
\hline Number of complaints & & \\
1 & $79.4(278)$ & $81.4(214)$ \\
2 & $18.6(65)$ & $14.8(39)$ \\
3 & $2.0(7)$ & $3.8(10)$ \\
Referrals & $18.0(63)$ & $17.2(45)$ \\
\hline Doctors & & \\
Age in years, mean (SD) & $50.9(7.5)$ & $51.3(6.4)$ \\
Males & $86.5(283)$ & $96.1(248)$ \\
\hline
\end{tabular}

Interobserver reliability between the evaluators was measured with a $\kappa$ statistic. Interobserver reliability of each ICE component as diagnostic/therapeutic or not (score 1 or 0 by the researchers) and of each ICE score (yes or no) by the student (score 1 or 0 by the researchers) were measured with a $\kappa$ statistic. ${ }^{31}$ In preparation for the study, 20 contacts were randomly selected and their transcriptions were discussed by three researchers; some discrepancies could be solved by discussion. Two discrepancies remained: the reasons for consulting a GP, 'I have a cold' as diagnostic/not diagnostic enough, and 'I want a reassurance' as diagnostic or therapeutic.

The different reasons for the encounter were categorised using the International Classification of Primary Care (ICPC), ${ }^{32,33}$ and the distribution was compared with a large-scale national registration network (Intego) to check the representativeness of the sample. ${ }^{34,35}$

\section{Statistical analysis}

For statistical analysis, SPSS (version 12.0, SPSS Inc) was used. Correlations were investigated between the expression of ICE and the following variables: age of patient and doctor; sex of patient and student; educational level of the patient; prescription of medication (new and follow-up); ICPC codes; and consultation versus home visit. Proportions were compared using Fisher's exact test. A logistic regression analysis was performed with presence or absence of new medication as the dependent variable, and with doctor, patient, student characteristics, and ideas, concerns, expectations as independent variables.

\section{RESULTS}

Thirty-six of the 39 students and all their GP trainers agreed to participate, leading to observations in 36 practices. Thirty-three out of the 36 GPs were male, with a mean age of 50.9 years (standard deviation [SD] 7.5 years, range 31-65 years). GPs had a mean of 17 trainees in the past; ${ }^{29}$ see Table 1 for characteristics of the patients and doctors for the new contacts and follow-up contacts.

In total, there were 613 contacts: 350 patients $(57.1 \%)$ had a new reason for the encounter, and 263 (42.9\%) were follow-up contacts; 92 (15.0\%) were home visits. On the registration date, the doctors had on average 17.0 consecutive patient contacts. When ICPC classifications of reasons for new encounters in this study were compared with the Intego national registration network ${ }^{34,35}$ (1 018000 registered reasons for a new encounter over 10 years) the same top five general areas of reasons for consulting were identified: respiratory, locomotor, digestive, skin, and general complaints. This showed that the present sample of contacts was representative for general practice in Belgium.

The inter-rater reliability of the scores of the presence/absence of ICE was $\kappa=0.87$ ( $\kappa>0.80$ is regarded as 'excellent agreement'). ${ }^{31}$ Inter-rater reliability of attribution of the ICE component to diagnosis or therapy was $\kappa=0.81$ and 0.85 respectively. Mean number of ICE elements per consultation was 1.54 (SD 0.54). In most contacts, ICE components were disclosed in relation to diagnosis or therapy. In 3\% $(n=18)$ ICE disclosure about the combination of diagnosis and therapy was identified.

\section{Expression of ideas, concerns, and expectations}

One or more ICE components were expressed in $83.0 \%$ (509/613) of all contacts, in $78.0 \%$ of contacts with a new reason for the encounter (273/350), and in $89.7 \%(236 / 263)$ of the follow-up contacts. Figure 1 presents the characteristics of ICE occurrence and their relative frequency distribution with combinations in all contacts, the new contact group, and the followup group.

Percentages of disclosed ideas, concerns, and expectations in each group are shown in Figure 2. Of all contacts, ideas were expressed in $35.2 \%(n=277)$, concerns in $42.3 \%(n=259)$, and expectations in $60.2 \%(n=369)$. In contacts with new reasons for the encounter, $54.0 \%$ ( $n=189)$ ideas, $47.4 \%(n=166)$ concerns, and $50.0 \%(n=175)$ expectations. In the follow-up contacts this was respectively $33.5 \%(n=$ 88 ) ideas, $35.4 \%(n=93)$ concerns, and $73.8 \%(n=$ 194) expectations.

During contacts with a new reason for an encounter, patients' ideas were more often voiced than during follow-up contacts (189/350 versus $88 / 263$, 54.0\% versus $33.5 \%, P<0.001$, odds ratio $[\mathrm{OR}]=2.33,95 \%$ confidence interval $[\mathrm{Cl}]=1.7$ to 3.3 ); similarly, concerns were also presented more often (166/350 


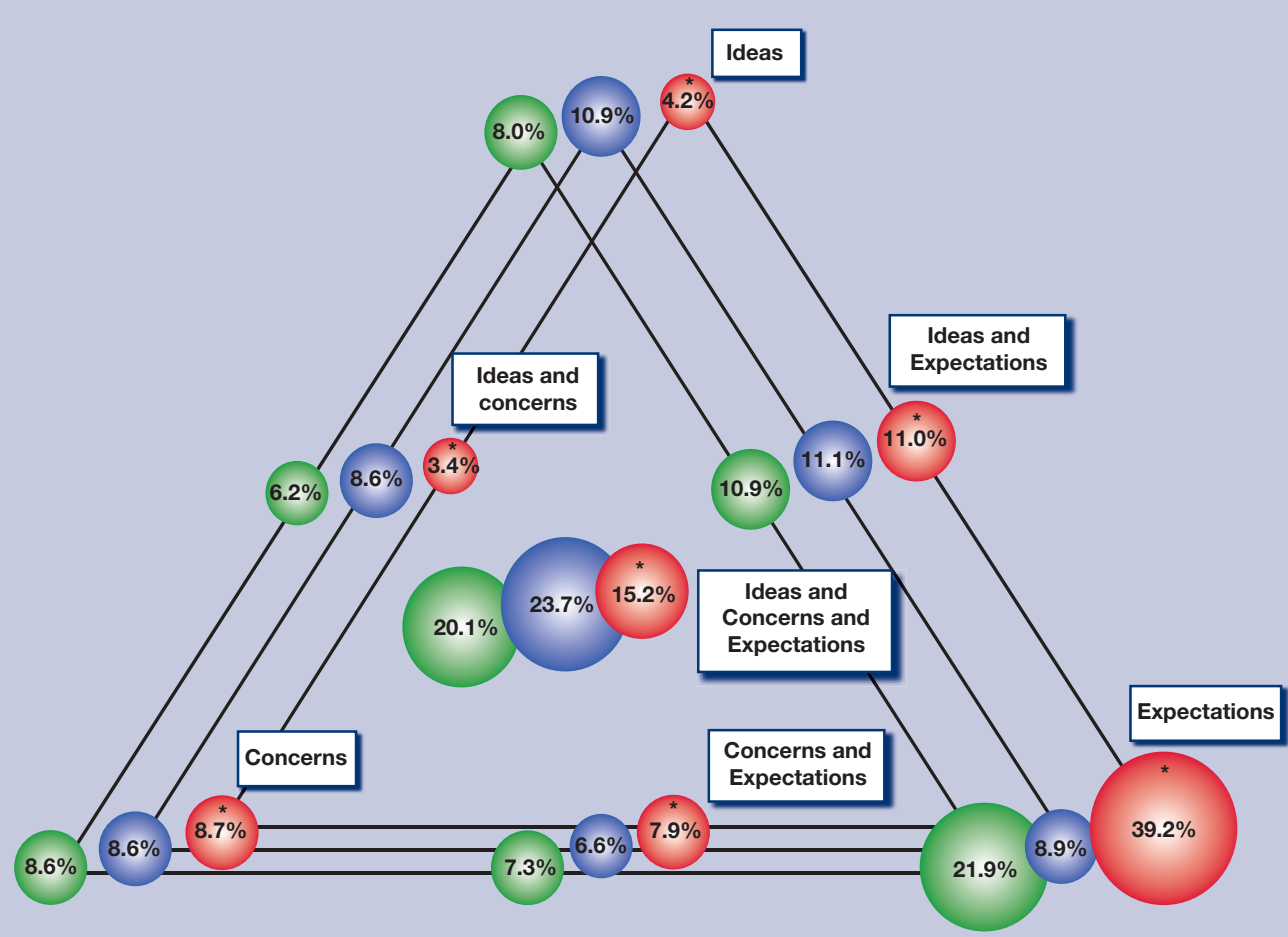

Percentage (number) of ideas, concerns, expectations and combinations in all contacts $(n=613)$. No ICE $17.0 \% n=104$

Percentage (number) of ideas, concerns, expectations and combinations in new contacts $(n=350)$. No ICE $22.0 \% n=77$

Percentage (number) of ideas, concerns, expectations (ICE) and

combinations in the follow-up group $(n=263)$. No ICE $10.3 \% n=27$
Figure 1. Percentage of ideas, concerns,

expectations, and combinations in all contacts, new contact group, and follow-up group.

Figure 2. Percentage (numbers) of ideas, concerns, expectations expressed in the different groups. versus $93 / 263,47.4 \%$ versus $35.4 \%, P=0.003$, OR = $1.65,95 \% \mathrm{Cl}=1.2$ to 2.3 ), whereas expectations mainly for continuation of established medication and for routine control - appeared more during the followup contacts $(194 / 263$ versus $175 / 350,73.8 \%$ versus $50.0 \%, P<0.001, \mathrm{OR}=2.81,95 \% \mathrm{Cl}=2.0$ to 4.0 ).

\section{ICE and new medication prescription}

Medication was prescribed in $69.8 \%(428 / 613)$ of all contacts; in $66.9 \%(234 / 350)$ of contacts with new reasons for an encounter; and in $73.8 \%$ (194/263) of the follow-up contacts. In a univariate analysis of the new reasons for encounters, fewer new drug prescriptions were found when concerns were voiced (Table 2; $P=$ $0.017, \mathrm{OR}=0.57,95 \% \mathrm{Cl}=0.4$ to 0.9 ); and fewer new drug prescriptions when expectations were expressed $(P=0.017, \mathrm{OR}=0.56,95 \% \mathrm{Cl}=0.4$ to 0.9 ). In none of the (sub)groups (new contacts and follow-up) was a difference found in (new) drug prescriptions in the presence of ideas $(P \geq 0.34$; Table 2). Of the contacts with new reasons for the encounter, 16 patients also received established medication, and three patients received only their established medication.

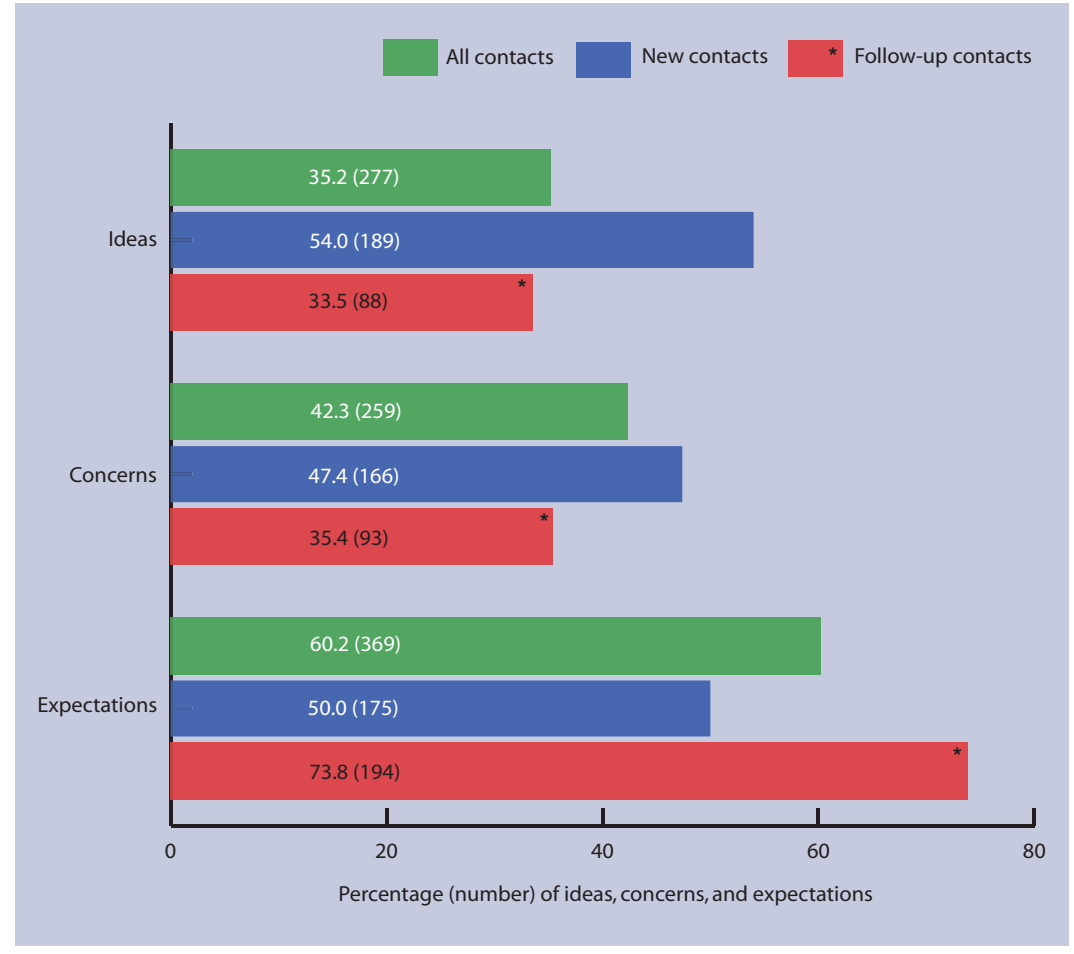


Table 2. ICE components and medication in all contacts, new reasons for an encounter, and follow-up contacts with $P$-value. ${ }^{a}$

\begin{tabular}{|c|c|c|c|c|c|c|c|c|c|c|c|c|}
\hline \multirow{2}{*}{$\begin{array}{l}\text { ICE } \\
\text { component } \\
\text { present }\end{array}$} & \multicolumn{4}{|c|}{$\begin{array}{c}\text { All contacts }(n=613)^{b} \\
\text { Medication (new + established) }\end{array}$} & \multicolumn{4}{|c|}{$\begin{array}{l}\text { New reasons for encounter }(n=350) \\
\text { New medication }\end{array}$} & \multicolumn{4}{|c|}{$\begin{array}{c}\text { Follow-up group }(n=263) \\
\text { Established }+ \text { adapted medication }\end{array}$} \\
\hline & No: 185 & Yes: 428 & $P$-value & OR $(95 \% \mathrm{Cl})$ & No: 116 & Yes: 234 & $P$-value & OR $(95 \% \mathrm{Cl})$ & No: 69 & Yes: 194 & $P$-value & OR $(95 \% \mathrm{Cl})$ \\
\hline & 89 & 188 & 0.340 & 0.85 (0.6 to 1.2$)$ & 64 & 125 & 0.760 & 0.93 (0.6 to 1.5$)$ & 25 & 63 & 0.570 & 0.85 (0.5 to 1.5$)$ \\
\hline ncerns & 92 & 167 & 0.016 & 0.65 (0.5 to 0.9$)$ & 66 & 100 & 0.017 & 0.57 (0.4 to 0.9$)$ & 26 & 67 & 0.064 & 0.87 (0.5 to 1.5$)$ \\
\hline pectations & 115 & 254 & 0.510 & 0.89 (0.6 to 1.3$)$ & 69 & 106 & 0.017 & $0.56(0.4$ to 0.9$)$ & 46 & 148 & 0.120 & 1.61 (0.9 to 2.9$)$ \\
\hline
\end{tabular}

${ }^{a} \mathrm{New}$ reasons for an encounter with concerns and expectations were less likely to receive medication. ${ }^{\circ} \mathrm{Comprising} 350$ new reasons for an encounter and 263 follow-up contacts. $\mathrm{OR}=$ odds ratio.

Of the contacts classified according to the ICPC chapter on respiratory complaints $(n=90)$, rather weak evidence was found for fewer antibiotic prescriptions when two or three ICE components were present, compared to the group with no or only one ICE component, namely $6 / 36$ versus $20 / 54$ prescriptions of antibiotics $(P=0.056$, OR $=0.34,95 \%$ $\mathrm{Cl}=0.10$ to 1.04 ).

In the contacts with a new reason for an encounter, logistic regression analysis showed that the presence of two ICE components, namely concerns $(P=0.037$, OR $=1.73,95 \% \mathrm{Cl}=1.03$ to 2.9$)$ and expectations $(P=$ $0.009, \mathrm{OR}=2.0,95 \% \mathrm{Cl}=1.2$ to 3.4 ), was associated with not prescribing new medication (dichotomised into the categories present/absent). However, other variables such as age of patient and doctor, sex of patient and student, and educational level of the patient were not significantly associated with medication prescription. After exclusion of contacts where there was a priori no need for new medication (request for certification, referral, blood test, X-ray: $n=128$ ), a logistic regression for the three ICE components remained significantly associated with not prescribing new medication: for ideas $(P=0.030, \mathrm{OR}=0.28,95 \%$ $\mathrm{Cl}=0.09$ to 0.88$)$, for concerns $(P=0.006$, OR $=0.21$, $95 \% \mathrm{Cl}=0.07$ to 0.67$)$, and for expectations $(P=0.032$, $\mathrm{OR}=0.34,95 \% \mathrm{Cl}=0.13$ to 0.91 ).

\section{DISCUSSION}

\section{Summary of main findings}

In quite a number of contacts with a new reason for an encounter (22\%), the ideas, concerns, or expectations of the patient remain undisclosed. A second main finding is that the expression of concerns and/or expectations is correlated with fewer prescriptions (univariate, logistic regression analysis, and also after exclusion of patients without an 'a priori need for medication'). Although the causal relationship remains uncertain, the observations may indicate that systematically disclosing the patients' real expectations and concerns could lead to less medication use. Furthermore, the fact that less antibiotic prescription was found in respiratory complaints (defined according to ICPC code), when two or three ICE components were present is concordant with this finding.

It was also found that ideas and concerns were expressed more often in contacts with new reasons for an encounter, and expectations were expressed more often in follow-up contacts.

Seventy-eight percent (273/350) of the new reasons for an encounter, and $77.3 \%$ (419/542) of the reasons for an encounter in which ICE components were expressed belonged to the top five ICPC codes for reasons for an encounter: this means that there was a good distribution of the ICE components among the different contact reasons.

As previously mentioned, in this study no ICE was found in $22.0 \%$ of the new contacts. This finding is similar to the results of the pilot study where ICE was not recorded in the medical record by the doctor in $29.7 \%$ of the new contacts. In the pilot study, five reasons were found for not disclosing or not registering: referral to a specialist, spot diagnosis (for example, skin infections such as zona, wounds, and epistaxis), registration of death, a problematic consultation, and referral by a family member. $^{15}$

\section{Strengths and limitations of the study}

Few studies are available on ideas, concerns, and expectations in family practice..$^{4,5,36,37}$ To the authors' knowledge, this is the first observational study that examines the frequency of ICE components in general practice consultations, and in relation to medication prescribing. There are several strengths to this study. First, real consultations were recorded, which show real doctor-patient interactions in contrast to, for example, simulated consultations in which GPs might adapt their behaviour. Trainee GPs were well trained to record the patients' and doctors' dialogue. Registration took place in 36 practices on the same day in a uniform way. The sample of registered contacts was representative of primary care after comparison with a large database (Intego).

In this conceptual study, the operational definitions 
of ICE could be refined. Although a high feasibility/acceptance of ICE was found in the pilot study, and high $\kappa$ values in the present study, it should be acknowledged that more studies about the validity of operational definitions of ICE are needed.

It is difficult to generalise the results of one study because doctors in teaching practices may be especially interested in communication skills and they may be aware of being observed. One of the weaknesses of the study is that there is no information available about the interobserver (student) reliability in scoring ICE elements. Yet at Ghent University, undergraduate medical students receive research training and training in ICE disclosure in which they learn the skills needed to ask questions about ICE. Furthermore, all recorded dialogue was double checked and only relevant text was accepted as having an ICE component if both raters agreed.

In this study there is no information about how clearly the problem was defined, or how the therapeutic options were outlined and what the consequences were of no treatment. Additionally, checking patients' understanding of the options as well as increasing patients' involvement in decision making are necessary steps. However, the fact that a relationship was found between the expression of ICE components and medication prescription indicates the potential value of this concept and that it may be applied either to the doctor or the patient. ${ }^{38}$

Indentifying and eliciting ICE components by GPs are key competences related to shared decision making, especially when deciding whether to prescribe medication. Perhaps what is found is that this step of exploring ICE leads to more conservative decisions. ${ }^{39}$

\section{Comparison with existing literature}

Only one trial in general practice was found where communication training had no influence on the rate of antibiotic prescriptions below an already unusually low level of $15.7 \% .^{13}$

\section{Implications for clinical practice and future research}

One suggestion for further qualitative research is to ask doctors why and when certain ICE components could or could not be assessed. Studies with students replaced by video, or in non-academic practices would be useful in order to study the association of ICE-based conversation and drug prescription rates.

\section{Funding body}

Not applicable

Ethical approval

The study was approved by the Ghent University Hospital, (2005/145)

\section{Competing interests}

The authors have stated that there are none

\section{Acknowledgements}

We thank the following GPs: D Anseeuw, E Bral, A Thoen, P Charlier, R Crevits, H De Langhe, Th De Maesschalck, L De Muynck, T Declercq, E Degeest, G Deneckere, L Feyen, W Geldhof, S Henderickx, P Heyerick, W Huba, F Hugelier, G Loncke, P Maudens, J De Maeseneer, P Muylaert, G Muylaert, L Present, L Schillemans, J Strobbe, J Van Acker, M Van De Putte, B Van De Velde, N Van der Maes, E Van Renterghem, P Vanbiervliet, G Vandenbussche, P Verdonck, J Verplanken, L Willems, and M Wybaillie. We thank Eva De Waele and Elke De Paepe for their help with the interratings. The principal investigator had full access to all of the data in the study and takes responsibility for the integrity of the data and the accuracy of the data analysis

\section{Discuss this article}

Contribute and read comments about this article on the Discussion Forum: http://www.rcgp.org.uk/bjgp-discuss

\section{REFERENCES}

1. Griffin SJ, Kinmonth AL, Veltman MW, et al. Effect on health-related outcomes of interventions to alter the interaction between patients and practitioners: a systematic review of trials. Ann Fam Med 2004; 2(6): 595-608.

2. Mead N, Bower P. Patient-centred consultations and outcomes in primary care: a review of the literature. Patient Educ Couns 2002; 48(1): 51-61.

3. Beck RS, Daughtridge R, Sloane PD. Physician-patient communication in the primary care office: a systematic review. J Am Board Fam Pract 2002; 15(1): 25-38.

4. Stewart M, Brown JB, Weston WW, et al. Patient-centered medicine: transforming the clinical method. 2nd edn. Oxon: Radcliffe Medical Press Ltd, 2003.

5. Stewart M. Towards a global definition of patient centred care. BM] 2001; 322(7284): 444-445.

6. Bensing J. Bridging the gap. The separate worlds of evidence-based medicine and patient-centered medicine. Patient Educ Couns 2000; 39(1): 17-25.

7. Silverman J, Kurtz S, Draper J. Skills for communicating with patients. Oxford: Radcliffe Medical Press, 1998.

8. Deveugele M, Derese A, De Maesschalck S, et al. Teaching communication skills to medical students, a challenge in the curriculum? Patient Educ Couns 2005; 58(3): 265-270.

9. Van Nuland M, Van Den Noortgate W, Degryse J, Goedhuys J. Comparison of two instruments for assessing communication skills in a general practice objective structured clinical examination. Med Educ 2007; 41(7): 676-683.

10. Pendleton D, Schofield T, Tate P, et al. The new consultation. Developing doctor-patient communication. Oxford: Oxford University Press, 2003.

11. Towle A, Godolphin W, Grams G, Lamarre A. Putting informed and shared decision making into practice. Health Expect 2006; 9(4): 321-332.

12. Kurtz S, Silverman J, Draper J. Teaching and learning communication skills in medicine. Oxon: Radcliffe Medical Press, 1998.

13. Briel M, Langewitz W, Tschudi $\mathrm{P}$, et al. Communication training and antibiotic use in acute respiratory tract infections. A cluster randomised controlled trial in general practice. Swiss Med Wkly 2006; 136(1516): 241-247.

14. Britten N, Ukoumunne O. The influence of patients' hopes of receiving a prescription on doctors' perceptions and the decision to prescribe: a questionnaire survey. BMJ 1997; 315(7121): 1506-1510.

15. Matthys J. Is het haalbaar om Ideeën, Zorgen en Verwachtingen van de patiënt (ICE-Regel) in het dossier te registreren? Een praktijkproject met 577 nieuwe aanmeldingsklachten. [Is it feasible to record patients' ideas, concerns, and expectations in the medical record? The results of 577 new reasons for an encounter in a teaching practice project.] Domus Med 2006; 8: 457-461.

16. Cartwright A, Anderson R. General practice revised. A second study of patients and their doctors. London: Tavistock, 1981.

17. Kravitz RL. Measuring patients' expectations and requests. Ann Int Med 2001; 134(9 pt 2): 881-888.

18. Keitz SA, Stechuchak KM, Grambow SC, et al. Behind closed doors: management of patient expectations in primary care practices. Arch Int Med 2007; 167(5): 445-452.

19. Marple RL, Kroenke K, Lucey CR, et al. Concerns and expectations in patients presenting with physical complaints. Frequency, physician 
perceptions and actions, and 2-week outcome. Arch Int Med 1997; 157(13): 1482-1488

20. Perron NJ, Secretan F, Vannotti M, et al. Patient expectations at a multicultural out-patient clinic in Switzerland. Fam Pract 2003; 20(4): 428-433.

21. Dawn AG, Santiago-Turla C, Lee PP. Patient expectations regarding eye care: focus group results. Arch Ophthalmol 2003; 121(6): 762-768.

22. Britten N. Patients' expectations of consultations. Patient pressure may be stronger in the doctor's mind than in the patient's. BMJ 2004; 328(7437): 416-417.

23. Cockburn J, Pitt S. Prescribing behaviour in clinical practice: patients' expectations and doctors' perceptions of patients' expectations - a questionnaire study. BMJ 1997; 315(7107): 520-523.

24. Himmel W, Lippert-Urbanke E, Kochen MM. Are patients more satisfied when they receive a prescription? The effect of patient expectations in general practice. Scand J Prim Health Care 1997; 15(3): $118-122$.

25. Van Driel ML, De Sutter A, Deveugele M, et al. Are sore patients who hope for antibiotics actually asking for pain relief? Ann Fam Med 2006 4(6): 494-499.

26. Butler CC, Rollnick S, Pill R, et al. Understanding the culture of prescribing: qualitative study of general practitioners' and patients' perceptions of antibiotics for sore throats. BMJ 1998; 317(7159): 637-642.

27. Lado E, Vacariza M, Fernández-González C, et al. Influence extended on drug prescribing by patients' attitudes and expectations and by doctors' perception of such expectations: a cohort and nested case-control study. J Eval Clin Pract 2008; 14(3): 453-459.

28. Little P, Dorward M, Warner G, et al. Importance of patient pressure and perceived pressure and perceived medical need for investigations, referral, and prescribing in primary care: nested observational study. BMJ 2004; 328(7437): 416-417.

29. Matthys J, De Meyere M, Mervielde I, et al. Influence of the presence of doctors-in-training on the blood pressure of patients: a randomised controlled trial in 22 teaching practices. J Hum Hypertens 2004; 18(11): 769-773.

30. Deveugele M, Derese A, De Maesschalck S, et al. Teaching communication skills to medical students, a challenge in the curriculum? Patient Educ Couns 2005; 58(3): 265-270.

31. Fleiss JL. Statistical methods for rates and proportions. 2 nd edn. New York: John Wiley and Sons, 1981.

32. Lamberts H, Brouwer HJ, Marinus AMF, Hofmans-Okkes IM. The use of ICPC in the Transition project. Episode oriented epidemiology in general practice. In: Lamberts H, Wood M, Hofmans-Okkes IM (eds). The international classification of primary care in the European community. Oxford: Oxford University Press, 1993: 45-93.

33. Wonca International Classification Committee. ICPC-2: International Classification of Primary Care. 2nd edn. Oxford: Oxford University Press, 1998.

34. Bartholomeeusen S, Buntinx F, De Cock I, Heyrman J. De prevalentie van ziekten in de huisartspraktijk: resultaten van de morbiditeitsregistratie. [The prevalence of illnesses in general practice: results of the morbidity registration.] INTEGO network Leuven: KU Leuven, Academisch Medisch Centrum voor Huisartsgeneeskunde, 2001.

35. Bartholomeeusen S, Kim C-Y, Mertens R, et al. The denominator in general practice, a new approach from the Intego database. Fam Pract 2005; 22(4): 442-447.

36. Roter DL, Stewart M, Putnam SM, et al. Communication patterns of primary care physicians. JAMA 1997; 277(4): 350-356.

37. McNutt RA. Shared medical decision making: problems, process, progress. JAMA 2004; 292(20): 2516-2518.

38. Elwyn G, Edwards A, Britten N. What information do patients need about medicines? 'Doing prescribing': how doctors can be more effective. BMJ 2003; 327(7419): 864-867.

39. Elwyn G, Edwards A, Kinnersly P. Shared decision-making in primary care: the neglected second half of the consultation. Br J Gen Pract 1999; 49(443): 477-482. 